\title{
Development of a Scale to Measure Followers' Satisfaction With Leaders Applicable in Cross-Cultural Studies
}

\author{
Arran Caza ${ }^{1} \&$ Barry Z. Posner ${ }^{2}$ \\ ${ }^{1}$ Bryan School of Business and Economics, University of North Carolina at Greensboro, Greensboro, USA \\ ${ }^{2}$ Leavey School of Business, Santa Clara University, Santa Clara, California, USA \\ Correspondence: Arran Caza, Bryan School of Business and Economics, University of North Carolina at Greensboro, \\ Greensboro, NC 27402, USA. E-mail: ajcaza@uncg.edu
}

Received: October 10, 2021

Accepted: November 3, 2021

Online Published: November 8, 2021

doi:10.5430/ijba.v12n6p17

URL: https://doi.org/10.5430/ijba.v12n6p17

\begin{abstract}
This study examined the cross-cultural performance of a new scale to measure followers' satisfaction with their leader. The scale was designed to give a generalizable measure of followers' response to their leader's behavior, one which is applicable across various leader-follower relationships and in different cultures. Using a diverse global sample of experienced followers who were familiar with their current leaders, the results supported the scale's utility. It performed well in all cultures, with good reliability and both convergent and discriminant validity. The scale offers a brief, widely applicable measure to advance the cross-cultural study of leadership.
\end{abstract}

Keywords: cross-cultural study, culture, follower satisfaction, leadership

\section{Introduction}

This study presents evidence for the cross-cultural utility of a new, short survey measure of followers' satisfaction with their leader. This is important because cultural diversity in organizations is growing and can be expected to continue doing so. Organizations' recruiting and operations are increasingly global, and communication technology makes inter-cultural contact ubiquitous (Durvasula \& Lysonski, 2015).

There is also increasing awareness of both ethical and performance benefits associated with greater diversity (Ely \& Thomas, 2020; Herring, 2017). However, as Adler and Aycan (2018) observe, even though cultural heterogeneity in organizations offers many opportunities, it typically is perceived as a challenge. Simply hiring more diverse staff is unlikely to lead to inclusion or performance gains (Edwards et al., 2019; Guillaume et al., 2017). Diverse staff need to be supported and genuinely made a part of the organization, and organizational leaders play a key role in the inclusion process (Mendenhall et al., 2012; Noon \& Ogbonna, 2020). Leaders set the tone for their organizations, shaping whether workforce diversity will be positive or negative in its consequences. Transformational leaders, for example, have been shown to improve group outcomes for culturally diverse teams (Kearney \& Gebert, 2009).

Leadership's potential role in bridging cultural differences in organizations makes the study of cross-cultural leadership vitally important, and there have been many investigations of the role of culture in leadership (Crede et al., 2019; Dickson et al., 2003; Hanges et al., 2016). However, culture-based leadership research frequently suffers a variety of weaknesses that limit the ability to draw firm conclusions, including vague operationalizations of culture, limited diversity, and measures of uncertain validity (Gupta, 2016; Tsui et al., 2007). The current research attempted to help address these issues by proposing a parsimonious measure of followers' satisfaction with their leader, focusing specifically on its validity in a global sample using an empirically supported model of culture.

\section{Key Concepts}

\subsection{Follower Satisfaction}

The aim of this study was to contribute to the understanding of how leaders can improve the experience of cultural diversity in organizations. In support of that aim, a measure was developed to examine the effects of leader behavior in cross-cultural settings. While leadership can have many effects in organizations (Hiller et al., 2011), the most fundamental is on followers' satisfaction with their leader (Brown \& Keeping, 2005; Dumdum et al., 2013). Satisfaction with one's leader refers to a positive affective appraisal of the leader's actions (Hackman \& Oldham, 
1975). Followers are more satisfied with leaders to the extent that those leaders provide what followers want and need (Locke, 1969; Lord et al., 1984). Such satisfaction is essential since leaders who do not have the faith and support of their followers are unlikely to succeed in benefiting the organization or its members (Kouzes \& Posner, 2017; Yang, 2016).

An ideal measure of followers' satisfaction with their leader would be short, as this would prevent survey fatigue and increase response quality, while also reflecting the core of the construct in a way that is consistent across cultures. The likeliest existing candidate is the satisfaction with supervisor sub-scale of the Job Diagnostic Survey (JDS; Hackman \& Oldham, 1975). That scale consists of three items: (1) The degree of respect and fair treatment I receive from my boss; (2) The amount of support and guidance I receive from my supervisor; and (3) The overall quality of the supervision I receive in my work.

These statements clearly relate to a follower's satisfaction with a formal leader, but they are also potentially limited in their applicability. Direct support and quality supervision are important leadership functions, but they do not pertain in all leader-follower relationships (Hunter et al., 2007; Reiche et al., 2017). For example, a follower who is in a supervisory position and relatively autonomous may not desire "quality supervision" from their leader. Similarly, cultural differences (e.g., power distance) may cause the notion of respect from a leader to signify quite different things. These issues are not shortcomings of the JDS scale per se, since it was specifically developed to refer to supervisors, not leaders in general.

However, these issues do highlight the utility of having a more broadly applicable measure. In the context of this effort, the next section describes the cultural model used in this study. Two other constructs, transformational leadership and job satisfaction, are described as they were employed to assess the convergent and discriminant validity of the new measure.

\subsection{Culture}

Culture refers to persistent beliefs, assumptions, perceptions, and practices shared by group members (Giorgi, Lockwood, \& Glynn; 2015). It is a relatively stable characteristic that distinguishes groups from one another (Tsui et al., 2007). Arising from shared environments, common experiences, and knowledge transmitted between individuals, culture tends to make members more similar to each other, relative to non-members (Hofstede, 2001; Inglehart \& Welzel, 2005).

Many models of culture have been in used in leadership and management studies, but the two most frequently used are Hofstede's (2001) dimensional model and Inglehart's (1997) developmental framework (Giorgi et al, 2015). Both have important strengths, but also significant weaknesses, which provided the impetus for a synthesis of the two models in which Beugelsdijk and Welzel (2018) analyzed a half million surveys of nationally representative samples from 110 countries. In that analysis, consistent with Hofstede (2001), personal values reliably distinguished members of different cultures. At the same time, consistent with Inglehart (1997), and refuting claims in Hofstede (2001), Beugelsdijk and Welzel (2018) found that cultural values changed over time (e.g., many cultures became more individualistic during the $20^{\text {th }}$ century). Moreover, their results showed that values were only one factor that defines culture, with history, economic development, and geography also being important differentiators.

Beugelsdijk and Welzel's (2018) analysis offers an integration of foundational work in the field based on a larger and more culturally diverse sample than any previous studies. For present purposes, one of their key findings is that the world may be described as consisting of four large cultural clusters: Anglo-Saxon \& Nordic; Latin American; European (except Nordic countries); and African \& Asian. While these clusters clearly contain significant heterogeneity, they are nonetheless similar enough in shared values, economic development, generational effects, and geo-political history to be identifiable groups (Beugelsdijk \& Welzel, 2018).

The identification of these four clusters is consistent with the growing trend in cross-cultural research that recognizes the distinction between culture and nation (Tung \& Stahl, 2018). Traditionally most studies used nationality as a proxy of culture (e.g., comparing Singaporeans to Americans; Caza \& Posner, 2017), but evidence shows that there are both significant value differences within countries and important similarities across countries (Taras et al., 2016). As a result, it is increasingly common for international management studies to equate culture with regions or other groupings of similar nations, rather than individual countries (e.g., House et al., 2004; Ronen \& Shenkar, 2013). This approach, using the four clusters in Beugelsdijk and Welzel (2018), was taken in the current study.

\subsection{Transformational Leadership}

Given the goal of assessing the cross-cultural utility of a new measure of followers' satisfaction with their leader, it was essential to include leadership behavior in the study, and that behavior needed to be cross-culturally relevant. 
Because culture shapes values and perceptions, it can have many important effects on leadership (Dorfman et al., 1997). Nonetheless, it appears that some aspects of leadership are consistent across cultures. One candidate for such universality, according to the GLOBE study (House et al., 2004), is that followers prefer leaders who exhibit behaviors associated with transformational leadership. More recently, Caza and colleagues (2021) found that leaders and followers from all cultures had similar perceptions of transformational leadership behavior.

Transformational leadership involves actions that promote cooperation by shaping followers' attitudes and beliefs (Mhatre \& Riggio, 2014; Podsakoff, MacKenzie, Moorman \& Fetter, 1990). Transformational leaders help to unite followers in pursuit of group goals by aligning personal and collective interests (Bass, 1985). Rather than influencing behavior through rewards and punishments, transformational leaders cause followers to feel trust, respect, and liking, and thus those followers want to do more than is formally required or rewarded (Kouzes \& Posner, 2017).

The transformational leadership construct is not without potential limitations, inlcuding an uncertain dimensionality, confounding cause and effect, and possible lack of distinctiveness from other aspects of leadership (van Knippenberg \& Sitkin, 2013). However, there is research that shows how variations in typologies of transformational leadership behavior tend to address the same core construct and have similar relationships with other constructs (Crede et al., 2019; Mhatre \& Reggio, 2014). Moreover, the measure of transformational leadership used in this study has comparable content and correlate relationships (Mhatre \& Reggio, 2014). It accesses observable behaviors, which reduces the problem of confounding transformational leadership with its effects, and it has demonstrated cross-cultural applicability, having been used for decades in dozens of countries (e.g., Isaksen et al., 2003; Posner \& Kouzes, 1988).

\subsection{Job Satisfaction}

A sound psychometric measure needs to assess its intended construct, and only that construct (Suddaby, 2010). Therefore, while the proposed new measure of satisfaction with one's leader needs face validity and an expected positive relationship with transformational leadership, it must also be distinguishable from related, but distinct constructs. The most useful construct to test this discriminant validity is job satisfaction. Job satisfaction is a complex construct, but fundamentally refers to a positive affective assessment of one's work (Judge et al., 2017). Since satisfaction with leadership can contribute to job satisfaction (Judge et al., 2020), and assessments of leadership often suffer from halo effects and similar affective bias (Behrendt et al; 2017; Brown \& Keeping, 2005), the constructs of job satisfaction and satisfaction with leadership are cognitively adjacent. Testing the discriminant validity of the satisfaction with leader scale using the job satisfaction sub-scale of the JDS (Hackman \& Oldham, 1975) provided a particularly stringent test.

\section{Method}

\subsection{Sample}

The sample was extracted from an online survey involving the direct reports of their managers who were attending various leadership development programs. Participation was voluntary and confidential. The sample was $40.3 \%$ female with a modal age of 33-40 years and respondents had considerable work experience (modal category greater than 10 years). Education levels varied from less than high school to graduate degrees, with the mode having completed undergraduate studies. Respondents represented 12 functional areas across 23 industries, with organizations ranging in size from less than 50 employees to over 10,000; and there were no substantive cultural differences associated with these factors. Only direct reports who had worked full-time with their organizational leaders for at least three years were included. Usable responses $(\mathrm{N}=1,725)$ were gathered from individuals representing 42 countries, including all four of the Beugelsdijk and Welzel (2018) cultural clusters: Anglo-Saxon \& Nordic $(\mathrm{N}=1,003)$; Latin American $(\mathrm{N}=144)$; European $(\mathrm{N}=176)$; and, African \& Asian $(\mathrm{N}=402)$.

\subsection{Measures}

Satisfaction with leader was assessed with three statements: "To what extent do you: (1) Agree that your manager is effective? (2) Trust your manager? and (3) Feel your manager is clear about what is expected from you?" This new scale was postulated to provide broad applicability and parsimony. Like the JDS scale, this one includes an overall assessment of effectiveness, but rather than focusing on supervision-specific support, it addresses two fundamental issues in all effective leader-follower relationships: the level of trust and the communication of specific guidance. Cross-national comparative studies suggest that followers in all cultures prefer leaders they trust and for those leaders to provide a clear, performance-oriented vision (House et al., 2004; Kouzes \& Posner, 2017). The items provide a brief assessment of followers' satisfaction with their leader and in a format that is applicable in all cultures. 
Transformational leadership was measured using the Leadership Practices Inventory (LPI; Kouzes \& Posner, 2003), which consists of 30 statements focused on leaders' observable behavior, rather than their intentions or character. For example, "[This leader] sets a personal example of what is expected from others" and "[This leader] encourages others to share an exciting dream of the future." Respondents indicated, on a 10-point Likert-scale, how frequently the leader engaged in each behavior.

The three-item JDS sub-scales of Satisfaction with supervisor and Job satisfaction were included in the study (Hackman \& Oldham, 1975). Respondents indicated on a 5-point scale the extent of their agreement with each statement. Culture reflected the cluster analysis results from Beugelsdijk and Welzel (2018). That study grouped 83 countries into the four cultural clusters. Respondents in the current data reported their national identity, and this identity was used to associate them with one of the four clusters.

\section{Analysis}

Several tests were performed in examining whether the new satisfaction with leader scale performed as expected. Tested first was whether the scales performed similarly across cultures and this was investigated by calculating and comparing the Cronbach's alpha reliability scores for every measure in each of the cultural clusters (Liu \& Weng, 2009). For example, comparing the reliability score for job satisfaction in the Anglo-Saxon \& Nordic cluster $(\alpha=.81)$ with that in the European cluster $(\alpha=.76)$ revealed a Cohen's $d$ score of .06 . The same calculation was conducted for every pairwise comparison across clusters. Second, an exploratory factor analysis (EFA) was performed in each cluster to examine the factor structure in the satisfaction with leader and satisfaction with supervisor items. Third, since the Anglo-Saxon \& Nordic sample was large, it was randomly split in half. One half of the Anglo-Saxon \& Nordic sample $(\mathrm{N}=502)$ was used in the previously mentioned EFA. The second half of the Anglo-Saxon \& Nordic sample $(\mathrm{N}=501)$ was used in a series of confirmatory factor analyses (CFA) and model comparisons to determine the convergent and discriminant validity of the new measure of satisfaction with leader.

\section{Results and Discussion}

The cross-cultural comparison of reliability scores for the four scales indicated that they performed equivalently in all clusters. The mean $d$ score in all pairwise comparisons of Cronbach's alpha values was only .17 (sd .08), which is a small difference (Cohen, 1988). This result suggests that the measures provided reliable assessments regardless of culture. Summary statistics for the sample (mean, standard deviation, reliability coefficients, and bivariate correlations) are shown in Table 1.

Table 1. Descriptive Statistics for the Sample*

\begin{tabular}{lccclll}
\hline Variable & Mean & sd & $\alpha$ & 1 & 2 & 3 \\
\hline 1. Satisfaction with leader & 4.04 & .69 & .71 & & & \\
& & & & & & \\
2. Satisfaction with supervisor & 4.12 & .74 & .87 & .72 & & \\
& & & & {$[.70, .74]$} & & \\
& & & & & & \\
3. Job satisfaction & 4.07 & .73 & .80 & .51 & .60 & \\
& & & & {$[.47, .54]$} & {$[.57, .63]$} & \\
& & & & & & \\
4. Transformational leadership & 7.84 & 1.53 & .97 & .72 & .73 & .44 \\
& & & & {$[.69, .74]$} & {$[.71, .75]$} & {$[.40, .48]$}
\end{tabular}

$* \mathrm{~N}=1,725$. Values in square brackets indicate the $95 \%$ confidence interval for the correlation.

All $p<.05$.

The exploratory factor analysis used six items: three of them measuring satisfaction with leader (the new scale) and three measuring satisfaction with supervisor (the established scale). In each cultural cluster, whether these items reflected one or two latent factors was examined. The results were consistent in all four clusters, strongly suggesting 
a single factor solution. In all four EFAs, the scree plot showed a clear elbow after the first factor, with the first eigenvalues being large (Anglo-Saxon \& Nordic 3.44, Latin American 2.82, European 3.17, African-Asian 3.90), while the second eigenvalues were small $(.58, .70, .78, .49$ respectively). Moreover, parallel analysis using 500 iterations suggested a single factor solution was preferred in every cluster (Hayton et al., 2004). These results are mutually consistent and suggest that the satisfaction with leader and satisfaction with supervisor scales were convergent in all four clusters. That is, they reflected the same underlying construct.

The size of the Anglo-Saxon \& Nordic sample allowed for further investigation using CFA. The half of that sample that was not used in the EFA was used to estimate and compare three different measurement models. Model 1 had three factors: satisfaction with leader, satisfaction with supervisor, and job satisfaction. It fit the data well $\left(\chi^{2}=\right.$ 112.91, $\mathrm{df}=24, \mathrm{CFI}=.96, \mathrm{RMSEA}=.05)$. The estimated correlation between the satisfaction with leader and satisfaction with supervisor scales was $.94(p<.01)$. Model 2 had two factors: one factor combining both the satisfaction with leader items and the satisfaction with supervisor items, plus a job satisfaction factor. It also fit the data well $(\chi 2=124.13, \mathrm{df}=26, \mathrm{CFI}=.96, \mathrm{RMSEA}=.05)$. Based on a chi-square difference test, using the scaling proposed by Satorra and Bentler (2001) to correct for small and potentially non-normal samples, Model 1 and Model 2 fit the data equally well (scaled $\Delta \chi^{2}=4.95, \mathrm{df}=2, p=.08$ ). Model 3 also had two factors: satisfaction with supervisor, and a single factor combining both the satisfaction with leader items and the job satisfaction items. This model did not fit the data well $\left(\chi^{2}=358.01, \mathrm{df}=26, \mathrm{CFI}=.86\right.$, RMSEA $\left.=.07\right)$, and the chi-square comparison showed that Model 3 had a significantly worse fit than Model 1 ( scaled $\Delta \chi^{2}=115.18, \mathrm{df}=2, p<.01$ ).

These results confirmed the EFA findings, showing measurement convergence between the satisfaction with leader and satisfaction with supervisor scales. The results also demonstrated the difference between the satisfaction with leader and job satisfaction scales (i.e., discriminant validity).

\section{Conclusion}

In sum, the results provide evidence supporting the cross-cultural utility of the new three-item satisfaction with leader scale. Equivalent reliability in all four cultural clusters of a global sample from 42 countries was found. Moreover, the new scale demonstrated convergent validity with an established measure of the same construct. It also had appropriate discriminant validity from a closely related, but nonetheless distinct, construct.

The new scale appears to measure satisfaction with the leader per se, rather than some generalized sense of satisfaction, and to do so in a fashion that should be applicable to a wide range of leader-follower contexts. For example, it would be useful in comparing respondents from various national, cultural, and geographical settings in their perceptions of leaders' behaviors and its impact on both leaders' effectiveness and workgroup performance. This measure provides a potentially robust tool for examining the effects of leadership between countries known to have quite different cultural characteristics (e.g., power distance and collectivistic vs. individualistic), which have been postulated as impacting the significance of various leadership behaviors (Hofstede, 2001; House et al. 2004). Scholars interested in leadership, especially in multinational and global settings, should find this new measure invaluable.

\section{References}

Adler, N. J., \& Aycan, Z. (2018). Cross-cultural interaction: What we know and what we need to know. Annual Review of Organizational Psychology and Organizational Behavior, 5, 307-333.

Bass, B. M. (1985). Leadership and performance beyond expectations. Free Press.

Beugelsdijk, S., \& Welzel, C. (2018). Dimensions and dynamics of national culture: Synthesizing Hofstede with $\begin{array}{llll}\text { Inglehart. Journal of } \quad \text { Cross-Cultural } & \text { Psychology, }\end{array}$ https://doi.org/10.1177/0022022118798505

Brown, D. J., \& Keeping, L. M. (2005). Elaborating the construct of transformational leadership: The role of affect. Leadership Quarterly, 16(2), 245-272. https://doi.org/10.1016/j.leaqua.2005.01.003

Caza, A., \& Posner, B. Z. (2017). The influence of nationality on followers' satisfaction with their leaders. Journal of Leadership, Accountability and Ethics, 14(3), 53-63.

Caza, A., Caza, B. B., \& Posner, B. Z. (2021). Transformational leadership across cultures: Follower perception and satisfaction. Administrative Sciences, 11(1), 32-42. https://doi.org/10.3390/admsci11010032

Cohen, J. (1988). Statistical power analysis for the behavioral sciences (2nd ed.). Lawrence Erlbaum Associates. 
Crede, M., Jong, J., \& Harms, P. (2019). The generalizability of transformational leadership across cultures: A meta-analysis. Journal of Managerial Psychology, 34(3), 139-155. https://doi.org/10.1108/JMP-11-2018-0506

Dickson, M. W., Den Hartog, D. N., \& Mitchelson, J. K. (2003). Research on leadership in a cross-cultural context: Making progress, and raising new questions. Leadership Quarterly, 14, 729-768. https://doi.org/10.1016/j.leaqua.2003.09.002

Dorfman, P. W., Howell, J. P., Hibino, S., Lee, J. K., Tate, U., \& Bautista, A. (1997). Leadership in Western and Asian countries: Commonalities and differences in effective leadership processes across cultures. Leadership Quarterly, 8(3), 233-274. https://doi.org/10.1016/S1048-9843(97)90003-5

Dumdum, U. R., Lowe, K. B., \& Avolio, B. J. (2013). A meta-analysis of transformational and transactional leadership correlates of effectiveness and satisfaction: An update and extension. In B. J. Avolio, \& F. J. Yammarino (Eds.), Transformational and Charismatic Leadership: The Road Ahead 10th Anniversary Edition (Vol. 5, pp. 39-70). Emerald Group Publishing Limited. https://doi.org/10.1108/S1479-357120130000005008

Durvasula, S., \& Lysonski, S. (2015). Cross-national applicability of a parsimonious measure of Acculturation to $\begin{array}{lllll}\text { Global Consumer } & \text { Culture. } & \text { Psychological }\end{array}$ https://doi.org/10.2466/01.08.PR0.116k29w6

Edwards, L. H., Holmes, M. H., \& Sowa, J. E. (2019). Including women in public affairs departments: Diversity is not enough. Journal of Public Affairs Education, 25(2), 163-184. https://doi.org/10.1080/15236803.2018.1565051

Ely, R. J., \& Thomas, D. A. (2020). Getting serious about diversity. Harvard Business Review, 98(6), 114-122.

Giorgi, S., Lockwood, C., \& Glynn, M. A. (2015). The many faces of culture: Making sense of 30 years of research on culture in organization studies. Academy of Management Annals, 9(1), 1-54. https://doi.org/10.1080/19416520.2015.1007645

Guillaume, Y. R. F., Dawson, J. F., Otaye-Ebede, L., Woods, S. A., \& West, M. A. (2017). Harnessing demographic differences in organizations: What moderates the effects of workplace diversity?. Journal of Organizational Behavior, 38(2), 276-303. https://doi.org/10.1002/job.2040

Gupta, N. (2016). Comment on: Cross-national applicability of a parsimonious measure of Acculturation to Global Consumer Culture. Psychological Reports, 118(2), 527-531. https://doi.org/10.1177/0033294116637731

Hackman, J. R., \& Oldham, G. R. (1975). Development of the Job Diagnostic Survey. Journal of Applied Psychology, 60, 159-170.

Hanges, P. J., Aiken, J. R., Park, J., \& Su, J. (2016). Cross-cultural leadership: Leading around the world. Current Opinion in Psychology, 8, 64-69. https://doi.org/10.1016/j.copsyc.2015.10.013

Hayton, J. C., Allen, D. G., \& Scarpello, V. (2004). Factor retention decisions in exploratory factor analysis: A tutorial on parallel analysis. Organizational Research Methods, 7, 191-205. https://doi.org/10.1177/1094428104263675

Herring, C. (2017). Is diversity still a good thing? American Sociological Review, 82(4), 868-877. https://doi.org/10.1177/0003122417716611

Hiller, N. J., DeChurch, L. A., Murase, T., \& Doty, D. (2011). Searching for outcomes of leadership: A 25-year review. Journal of Management, 37(4), 1137-1177. https://doi.org/10.1177/0149206310393520

Hofstede, G. (2001). Culture's consequences: Comparing values, behaviors, institutions, and organizations across nations (2nd ed.). Sage Publications.

House, R. J., Hanges, P. J., Javidan, M., Dorfman, P. W., \& Gupta, V. (Eds.). (2004). Culture, leadership, and organizations: The GLOBE study of 62 societies. Sage Publications.

Hunter, S. T., Bedell-Avers, K. E., \& Mumford, M. D. (2007). The typical leadership study: Assumptions, implications, and potential remedies. Leadership Quarterly, 18, 435-446. https://doi.org/10.1016/j.leaqua.2007.07.001

Inglehart, R. (1997). Modernization and postmodernization: Cultural, economic, and political change in 43 societies. Princeton University Press.

Inglehart, R., \& Welzel, C. (2005). Modernization, cultural change, and democracy: The human development sequence. Cambridge University Press. 
Isaksen, S. G., Babij, B. J., \& Lauer, K. J. (2003). Cognitive styles in creative leadership practices: Exploring the relationship between level and style. Psychological Reports, 93(3), 983-994. https://doi.org/10.2466/pr0.2003.93.3.983

Judge, T. A., Weiss, H. M., Kammeyer-Mueller, J. D., \& Hulin, C. L. (2017). Job attitudes, job satisfaction, and job affect: A century of continuity and of change. Journal of Applied Psychology, 102(3), 356-374. https://doi.org/10.1037/ap10000181

Judge, T. A., Zhang, S., \& Glerum, D. R. (2020). Job satisfaction. In V. I. Sessa, \& N. A. Bowling (Eds.), Essentials of Job Attitudes and Other Workplace Psychological Constructs (pp. 207-241). Routledge.

Kearney, E., \& Gebert, D. (2009). Managing diversity and enhancing team outcomes: The promise of transformational leadership. Journal of Applied Psychology, 94(1), 77.

Kouzes, J. M., \& Posner, B. Z. (2003). LPI: Leadership Practices Inventory (4th ed.). Wiley.

Kouzes, J. M., \& Posner, B. Z. (2017). The leadership challenge: How to make extraordinary things happen in organizations (6th ed.). Wiley.

Liu, H.-Y., \& Weng, L.-J. (2009). An effect size index for comparing two independent alpha coefficients. British Journal of Mathematical and Statistical Psychology, 62(2), 385-400. https://doi.org/10.1348/000711008X315518

Locke, E. A. (1969). What is job satisfaction? Organizational Behavior and Human Performance, 4(4), 309-336. https://doi.org/10.1016/0030-5073(69)90013-0

Lord, R. G., Foti, R. J., \& De Vader, C. L. (1984). A test of leadership categorization theory: Internal structure, information processing, and leadership perceptions. Organizational Behavior and Human Performance, 34(3), 343-378.

Mendenhall, M. E., Reiche, B. S., Bird, A., \& Osland, J. S. (2012). Defining the "global" in global leadership. Journal of World Business, 47(4), 493-503.

Mhatre, K. H., \& Riggio, R. E. (2014). Charismatic and transformational leadership: Past, present, and future. In D. Day (Ed.), Oxford Handbook of Leadership and Organizations (pp. 221-240). Oxford University Press.

Noon, M., \& Ogbonna, E. (2020). Controlling management to deliver diversity and inclusion: Prospects and limits. Human Resource Management Journal. https://doi.org/10.1111/1748-8583.12332

Posner, B. Z., \& Kouzes, J. M. (1988). Development and validation of the Leadership Practices Inventory. Educational and Psychological Measurement, 48(2), 483-496. https://doi.org/10.1177/0013164488482024

Reiche, B. S., Bird, A., Mendenhall, M. E., \& Osland, J. S. (2017). Contextualizing leadership: A typology of global leadership roles. Journal of International Business Studies, 48(5), 552-572. https://doi.org/10.1057/s41267-016-0030-3

Ronen, S., \& Shenkar, O. (2013). Mapping world cultures: Cluster formation, sources and implications. Journal of International Business Studies, 44(9), 867-897. https://doi.org/10.1057/jibs.2013.42

Satorra, A., \& Bentler, P. M. (2001). A scaled difference chi-square test statistic for moment structure analysis. Psychometrika, 66(4), 507-514. https://doi.org/10.1007/BF02296192

Suddaby, R. (2010). Construct clarity in theories of management and organization. Academy of Management Review, 35, 346-357.

Taras, V., Steel, P., \& Kirkman, B. L. (2016). Does country equate with culture? Beyond geography in the search for cultural boundaries. Management International Review, 56(4), 455-487. https://doi.org/10.1007/s11575-016-0283-x

Tsui, A. S., Nifadkar, S. S., \& Ou, A. Y. (2007). Cross-national, cross-cultural organizational behavior research: Advances, gaps, and recommendations. Journal of Management, 33(3), 426-478. https://doi.org/10.1177/0149206307300818

Tung, R. L., \& Stahl, G. K. (2018). The tortuous evolution of the role of culture in IB research: What we know, what we don't know, and where we are headed. Journal of International Business Studies, 49(9), 1167-1189. https://doi.org/10.1057/s41267-018-0184-2 
van Knippenberg, D., \& Sitkin, S. B. (2013). A critical assessment of charismatic-transformational leadership research: Back to the drawing board? Academy of Management Annals, 7(1), 1-60. https://doi.org/10.1080/19416520.2013.759433

Yang, Y.-F. (2016). Examining competing models of transformational leadership, leadership trust, change commitment, and job satisfaction. Psychological Reports, 119(1), 154-173. https://doi.org/10.1177/0033294116657586

\section{Copyrights}

Copyright for this article is retained by the author(s), with first publication rights granted to the journal.

This is an open-access article distributed under the terms and conditions of the Creative Commons Attribution license (http://creativecommons.org/licenses/by/4.0/). 